\title{
Strategi Double Skin Fasade pada Bangunan Kampus National Central University dalam Menurunkan Kebutuhan Energi Pendinginan
}

\author{
Cynthia Permata Dewi ${ }^{1}$, Rong-Yau Huang² dan Agung Murti Nugroho ${ }^{3}$ \\ ${ }_{1}^{1}$ Magister Teknik Sipil, Universitas Brawijaya \\ 2 Departemen manajemen konstruksi, National Central University, Taiwan \\ ${ }_{3}^{3}$ Jurusan arsitektur, Universitas Brawijaya \\ Alamat Email penulis : cwit_gals@yahoo.com
}

\begin{abstract}
ABSTRAK
Teknologi double skin façade (DSF) merupakan salah satu teknologi fasade tingkat lanjut yang dapat digunakan dalam membantu menghemat pengunaan energi bangunan. Teknologi bangunan hemat energi menjadi cukup penting dalam siklus operasional bangunan dan membantu menunjang kenyaman penghuni bangunan. Penelitian ini bertujuan untuk melihat pengaruh dari kombinasi modifikasi jarak dan pengunaan material DSF yang berbeda pada gedung kuliah di National Central University, Taiwan, dengan iklim panas lembab. DesignBuilder-EnergyPlus merupakan software yang digunakan dalam membantu melakukan simulasi energi pada studi kasus terkait. Bangunan yang digunakan dalam penelitian ini merupakan bangunan konvesional single skin, yang selanjutnya disebut sebagai base case. Teknologi DSF diaplikasikan pada fasade bangunan yang memiliki nilai heat gain yang tinggi. Hasil penelitian menunjukkan kombinasi jarak air gap $1.2 \mathrm{~m}$ dan penggunaan material kaca double glazed Low E mampu menurunkan penggunaan konsumsi energi untuk pendinginan sebesar $31.28 \%$. dengan adanya penurunan energi yang cukup besar, membuktikan bahwa teknologi DSF ini juga sesuai digunakan pada bangunan dengan iklim panas lembab seperti Taiwan.
\end{abstract}

Kata kunci: double skin facade, air gap, material, energi

\begin{abstract}
Building façade plays significant role in building energy efficiency and sustainability. Double Skin Façade (DSF) strategy comes as one of solution in advance building façade design technology. The aim of this study is to observe the performance of DSF configuration (air gap width) and materials in terms of reducing cooling energy for energy efficiency in case study buildings in hot humid climate in Taiwan. DesignBuilderEnergyPlus was used as simulation tool in this study. Two scenario based on the placement of DSF strategy were conducted. The results show that combination of $1.2 \mathrm{~m}$ air gap and double glazed Low E could reduce the cooling energy demand up to $31.28 \%$. This study proved that DSF strategy is possible to be applied on hot humid climate such as Taiwan.
\end{abstract}

Keywords: double skin façade, air gap, material, energy 


\section{Pendahuluan}

Efek rumah kaca akibat aktivitas manusia memberikan dampak yang cukup signifikan terhadap lingkungan. Menurut catatan IEA (International Energy Agency), gedung dan bangunan merupakan sektor yang paling besar dalam konsumsi energi pada level dunia. Lebih lanjut lagi biro energi Taiwan mencatat sektor gedung dan bangunan di Taiwan mengkonsumsi energi listrik terbesar kedua (39\%) setelah sektor industri (Ho, 2011). Kebutuhan listrik pada bangunan sebagian besar dimanfaatkan untuk memenuhi kebutuhan HVAC (Heating Ventilating and Air Conditioning). Energi untuk kebutuhan AC pada aktifitas sehari-hari mencapai kisaran 40\%, sedangkan kebutuhan pencahayaan mencapai 35\%.

Untuk mengurangi efek emisi gas rumah kaca, terdapat dua strategi yang bisa digunakan. Pertama, dengan mengurangi suplai energi dan yang kedua melalui pengolahan desain bangunan, sehingga strategi efisiensi dan hemat energi dengan mengurangi kebutuhan konsumsi energi bangunan dapat dicapai. Beberapa penelitian sebelumnya menyebutkan bahwa fasade bangunan memainkan peranan penting dalam keberlanjutan dan efisiensi energi bangunan (Concina, Sadineni, \& Boehm, 2011; Liu, n.d.; Yellamraju, 2004).

Tujuan utama dari desain fasade bangunan pada area dengan iklim panas lembab adalah untuk mengurangi solar gain. Teknologi Double Skin Façade (DSF) merupakan salah satu teknik fasade bangunan yang dapat membantu mengurangi solar gain pada bangunan. kemampuan teknologi DSF ini dalam membantu efisiensi energi bangunan dan kemampuannya untuk beradaptasi dengan baik dengan lingkungan menjadikan teknologi ini mulai berkembang dan diaplikasikan. Setiap desain DSF sangat bervariatif kondisi fisik dan performanya, dan desain DSF ini harus sangat memperhatikan kondisi iklim dimana teknologi ini diaplikasikan.

Kemampuan teknologi DSF ini dalam mengurangi beban panas dan pendinginan bangunan menjadikan teknologi ini banyak didiskusikan dan diaplikasikan, terutama pada negara-negara di Eropa. Penggunaan DSF pada iklim panas lembab seperti Taiwan belum pernah dilakukan. Dengan kemampuan DSF yang telah banyak didiskusikan dan diaplikasikan di Eropa, maka penelitian ini akan menguji kemungkinan penggunaan teknologi ini pada bangunan di Taiwan serta kemampuannya dalam mengurangi kebutuhan energi AC pada bangunan di Taiwan. Konfigurasi jarak DSF dan penggunaan material kaca yang berbeda-beda pada dinding terluar dalam teknologi ini akan digunakan pada saat yang bersamaan untuk mengetahui bagaimana pengaruhnya terhadap pengurangan kebutuan energi AC, apabila kedua parameter tersebut digunakan secara bersamaan.

\section{Bahan dan Metode}

\subsection{Double skin fasade}

Teknologi DSF ini dikenalkan pertama kali pada awal tahun 1849 dan diaplikasikan pertama kali pada bangunan Steiff-Factory di Jerman (Mulyadi, 2012; Wong, 2008; Yellamraju, 2004). Claesse dan Deherde dalam Alessi (Alessi, 2008) menyebutkan bahwa DSF merupakan dinding bangunan tambahan yang pada umumnya transparan dan dipasang di atas dinding eksisting. Adanya jarak antara dinding tambahan dan dinding eksisting berfungsi sebagai insulasi bangunan. Menurut Yagoub (Yagoub, Appleton, \& Stevens, 2010), komponen utama DSF yang terdapat pada Gambar 1 antara lain dinding 
terluar (outer skin), jarak (cavity/ air gap) dan dinding bagian dalam/ dinding eksisting (inner skin). Pada beberapa aplikasi dapat diletakkan shading device pada jarak antara kedua dinding untuk dapat membantu mengurangi panas yang masuk ke dalam bangunan.

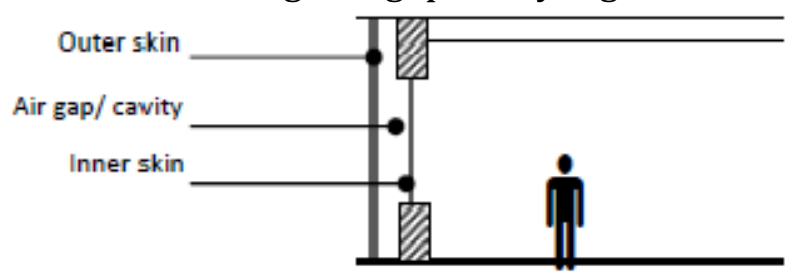

Gambar 1. Komponen DSF

Tipe DSF (Tascon, 2008), diklasifikan menjadi empat macam berdasar bentuk penyekatan jarak antara dinding dalam dan luar (Gambar 2). Tipe pertama yaitu box window façade yaitu DSF yang jarak antara dinding luar dan dalam disekat secara vertikal dan horizontal mengikuti bentuk jendela dan berfungsi untuk menghindari transmisi suara dan asap antar ruangan. Tipe yang kedua yaitu shaft box façade yaitu DSF tipe box window yang terhubung dengan saft vertikal yang menerus. Tipe ketiga yaitu corridor façade yaitu DSF yang ruang jaraknya disekat secara horizontal sesuai dengan pembagian jumlah lantai bangunan. Tipe yang terakhir yaitu multistory façade yaitu DSF yang ruang antara nya tidak dibagi dan menerus, lubang bukaan untuk ventilasi terdapat di bagian atas dan bawah fasade saja.

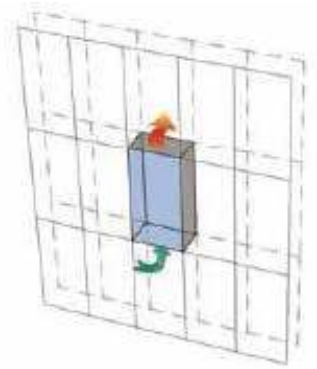

Box window

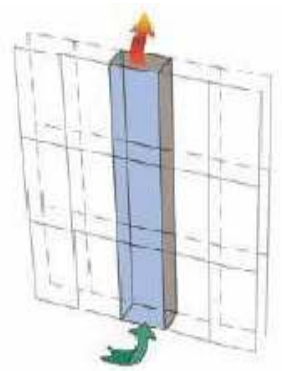

Shaft box

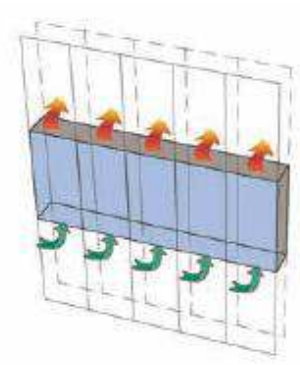

Corridor façade

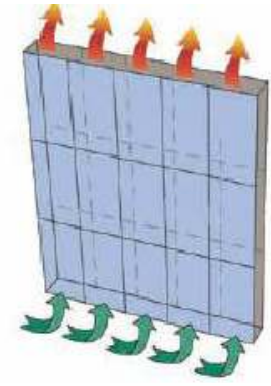

Multistory

Gambar 2. Tipe DSF

(Sumber: Tascon, 2008)

Terdapat dua karakter penting pada DSF yang dimanfaatkan untuk mengurangi panas yang masuk ke dalam bangunan, sehingga teknologi ini mampu mebantu menurunkan kebutuhan energi untuk AC. Karakter tersebut adalah transfer panas dan thermal buoyancy atau stack effect.

\section{$2.2 \quad$ Metode}

Penelitian ini menggunakan studi kasus dalam meneliti modifikasi variabel DSF dan performanya terhadap kemampuan mengurangi kebutuhan energi AC bangunan. Tahapan penelitian ini dimulai dengan studi pustaka dan pemilihan objek sebagai studi kasus. Gedung Kwoh Ting pada National Central University (NCU) Taiwan merupakan objek yang digunakan sebagai studi kasus pada penelitian ini (Gambar 3). 


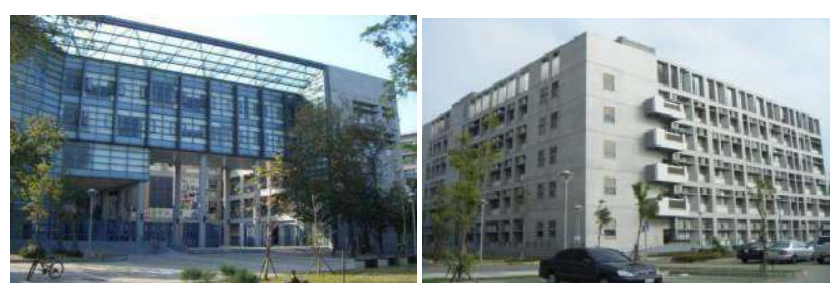

Gambar 3. Gedung Kwoh Ting, NCU, Taiwan

Gedung Kwoh Ting ini berbentuk kompak persegi dengan ketinggian antar lantai 4.5m. Curtain wall hanya diaplikasikan pada dinding sebelah timur bangunan, sedangkan finishing dinding sisi lainnya merupakan kombinasi dinding masif dan bukaan jendela. Spesifikasi material yang digunakan pada studi kasus ini ditampilkan pada Tabel 1.

Tabel 1. Material Properties Gedung Kwoh Ting

\begin{tabular}{lll}
\hline Construction & Material layer & $\mathrm{U}-$ Value $\left(\mathrm{W} / \mathrm{m}^{2} \mathrm{~K}\right)$ \\
\hline $\begin{array}{l}\text { External wall } \\
\text { (Basement) }\end{array}$ & $\begin{array}{l}\text { Cement plaster-reinforced concrete- } \\
\text { cement plaster }\end{array}$ & 3.879 \\
\hline 1-5 floor & $\begin{array}{l}\text { Cast concrete-plaster-brickwork- } \\
\text { plaster }\end{array}$ & 1.833 \\
\hline Curtain Wall & $10 \mathrm{~mm}+12 \mathrm{~A}+10 \mathrm{~mm}$ Single low E & 1.472 \\
\hline Window & $6 \mathrm{~mm}$ clear glass & 5.778 \\
\hline Interior partition & Paint-plaster-brickwork-plaster-paint & 2.216 \\
\hline Floor & Sand-reinforced concrete & 2.842 \\
\hline Flat roof & $\begin{array}{l}\text { Asphalt-reinforced concrete-gap- } \\
\text { plaster }\end{array}$ & 2.136 \\
\hline
\end{tabular}

Tahapan selanjutnya adalah analisa data iklim yang akan digunakan sebagai input pada tahapan simulasi model. Dalam kurun waktu dua tahun terakhir dari 2010-2012, kondisi iklim terekstrim rata-rata dialami pada kurun waktu 2010, sehingga data iklim tahunan yang digunakan pada penelitian ini menggunakan data selama tahun 2010. Data diperoleh dari stasiun iklim terdekat yang berada di departemen athmospheric NCU. Analisa data iklim dimulai dengan mengolah data iklim mentah dengan jangka watu pencatatan per menit dalam format (.obs) menjadi data per jam dalam format spreadsheet (.xls). Setelah data per jam dalam periode waktu satu tahun telah siap, tahapan selanjutnya adalah memproses data iklim dalam spreadsheet menjadi data iklim dalam format (.epw) yang diperlukan pada program simulasi menggunakan (.epw) generator.

Dua parameter utama akan dimodifikasi pada penelitian ini, yang pertama adalah air gap/cavity (jarak antara outer dan inner skin bangunan) dan material yang digunakan pada outer skin (dinding terluar) bangunan, dalam hal ini adalah kaca. Untuk parameter air gap, akan digunakan empat jarak berbeda mulai dari $0.3 \mathrm{~m}, 0.6 \mathrm{~m}, 0.9 \mathrm{~m}$ sampai $1.2 \mathrm{~m}$ (Gambar 4 ).

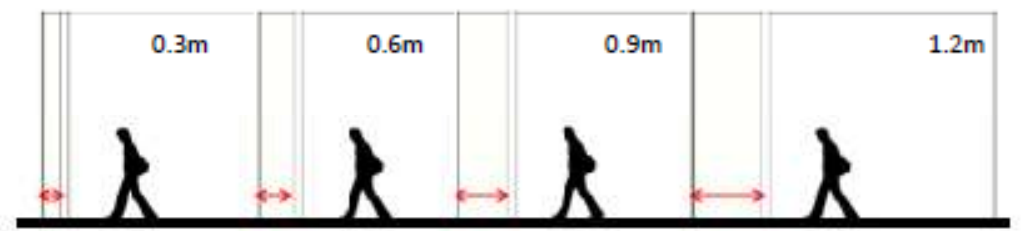

Gambar 4. Variasi Lebar Air Gap 
Untuk modifikasi material kaca pada bagian outer skin bangunan akan digunakan empat jenis material berbeda yang mudah didapat dan biasa digunakan pada bangunan dengan strategi DSF (Tabel 2). Selain itu penggunaan kaca dengan spesifikasi performa yang tinggi, double glazed Low E juga akan diteliti dan dilihat pengaruhnya perhadap variabel dependen, dalam hal ini adalah energi untuk pendinginan bangunan.

Tabel 2. Material Properties Kaca DSF

\begin{tabular}{lllll}
\hline & Clear glass & Reflective glass & Laminated glass & Double glazed Low E \\
\hline SHGC & 0.794 & 0.6 & 0.495 & 0.219 \\
\hline $\begin{array}{l}\text { Direct solar } \\
\text { transmission }\end{array}$ & 0.74 & 4.97 & 0.443 & 0.128 \\
\hline $\begin{array}{l}\text { Light } \\
\text { transmission }\end{array}$ & 0.86 & 0.507 & 0.792 & 0.229 \\
\hline U value & 5.666 & 5.582 & 3.161 & 1.764 \\
\hline
\end{tabular}

Pada penelitian ini software yang digunakan adalah software DesignBuilderEnergyPlus 3.0.0.105 trial version. Software ini dipilih untuk digunakan pada penelitian ini karena beberapa kelebihannya antara lain karena solver enginenya sangat kuat yaitu EnergyPlus, yang sudah sangat terpercaya keakuratannya dalam studi simulasi energi. Selain itu, program ini juga telah mengunakan metode kesetimbangan thermal untuk kalkulasi energi dan telah sesuai dengan standar ASHRAE (American Society of Heating, Refrigerating and Air Conditioning Engineers).

Sebelum dilakukan simulasi terhadap model DSF, maka dilakukan simulasi terhadap model dasar dengan kondisi eksisting terlebih dahulu (Azarbayjani, 2012). Hal ini dilakukan untuk dapat membandingkan dan melihat performa bangunan sebelum dan sesudah diaplikasikannya strategi DSF ini. Langkah pertama sebelum menjalankan simulasi adalah membangun model pada ruang simulasi dengan mengimpor denah 2D CAD (computer aided drawing) untuk setiap lantai. Model dibangun per lantai dengan detail partisi interior yang disederhanakan karena limitasi program untuk software yang digunakan tidak boleh melebihi lima puluh zona. Model dibangun dan diletakkan di atas komponen blok yang difungsikan sebagai ground dengan perilaku transfer panas yang sesuai (Gambar 5).
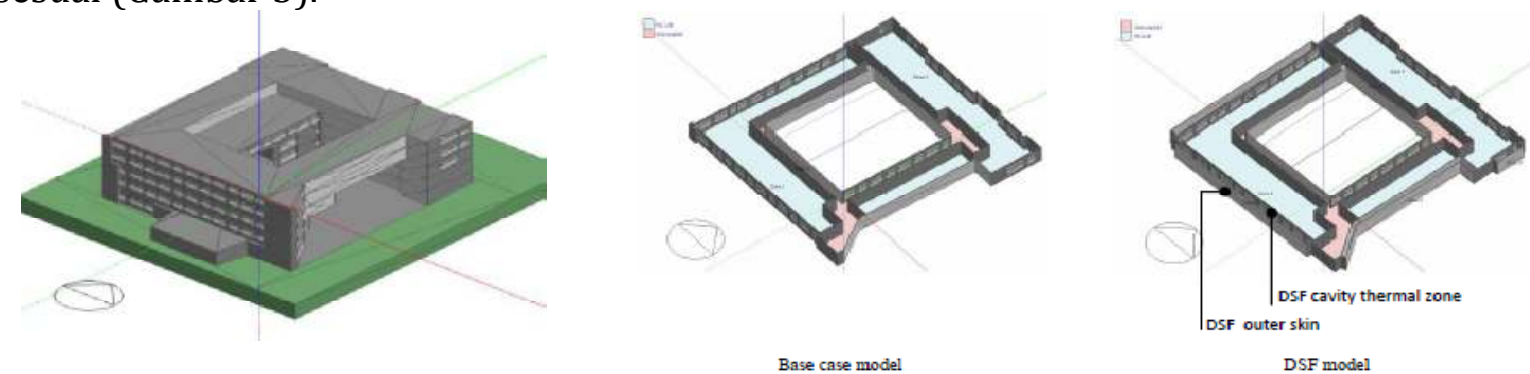

Gambar 5. Model Dasar dan Model DSF Pada Program Simulasi

Untuk setting aktifitas pada tiap zona mengikuti dengan fungsi ruang masingmasing. Beberapa asumsi untuk input simulasi digunakan karena terbatasnya informasi. Untuk pengaturan zona pada model DSF, pengaturan berdasar kepada base rule simulasi model DSF oleh software ini, yaitu unoccupied cavity with natural ventilation (karena pada penelitian ini jenis penghawaan DSF adalah ventilasi alami maka sistem ventilasi yang 
diatur pada program untuk zona air gap DSF adalah ventilasi alami). Beberapa setting lainnya ditampilkan pada Tabel 3.

Tabel 3. Input Simulasi

\begin{tabular}{ll}
\hline Occupancy & 0.11 people $/ \mathrm{m}^{2}$ \\
\hline Metabolic activity & Working involving walking etc \\
\hline Indoor set point & $24^{\circ} \mathrm{C}$ \\
\hline Target iluminance & 400 lux \\
\hline HVAC type & Split system \\
\hline Cooling CoP & 2.97 \\
\hline \multicolumn{2}{l}{ Electricity from grid } \\
\hline Infiltration & $0.7 \mathrm{ACH}$ \\
\hline Lighting & $5 \mathrm{~W} / \mathrm{m}^{2}$ \\
\hline Circulation area is unconditioned & \\
\hline DSF zone is set to be cavity naturally ventilated \\
\hline
\end{tabular}

Ada dua skenario penempatan DSF yang akan dijalankan dalam penelitian ini. Scenario yang pertama adalah mengaplikasikan DSF pada dinding-dinding dengan sisi terpanas berdasarkan standar perhitungan heat gain oleh ASHRAE (Vechaphutti, P.E., n.d.).

$$
\mathrm{q}=(\mathrm{Uw} \times \mathrm{Aw} \times \mathrm{TDeq})+(\mathrm{Uf} \times \mathrm{Af} \times \Delta \mathrm{T})+(\text { Af } \times \mathrm{SC} \times \mathrm{SF})
$$
dimana:

$\mathrm{q}=$ heat gain pada dinding bangunan (W)

$\mathrm{Uw}=$ thermal transmittance pada dinding massif $\left(\mathrm{W} / \mathrm{m}^{2}{ }^{\circ} \mathrm{C}\right)$

Aw = luasan dinding massif $\left(\mathrm{m}^{2}\right)$

TDeq $=$ equivalent temperature difference $\left({ }^{\circ} \mathrm{C}\right)$

Af $\quad=$ luas area transparan $\left(\mathrm{m}^{2}\right)$

Uf $\quad=$ thermal transmittance pada sisi transparan $\left(\mathrm{W} / \mathrm{m}^{2}{ }^{\circ} \mathrm{C}\right)$

$\Delta \mathrm{T} \quad=$ perbedaan temperature indoor dan outdoor $\left({ }^{\circ} \mathrm{C}\right)$

$\mathrm{SC} \quad=$ shading coefficient

$\mathrm{SF} \quad=$ solar factor $\left(\mathrm{W} / \mathrm{m}^{2}\right)$

Sedangkan scenario kedua adalah dengan mengaplikasikan DSF pada seluruh dinding fasade bangunan.

\section{Hasil dan Pembahasan}

Simulasi model dasar dilakukan pada model dengan kondisi eksisting fasade single skin. Hasil simulasi model dasar menunjukkan bahwa total konsumsi energi bangunan untuk pendinginan dalam kurun waktu satu tahun adalah 250,530 kWh atau sebesar $18.84 \%$ dari total seluruh konsumsi energi bangunan.

Sebelum menjalankan simulasi untuk skenario pertama, maka dilakukan perhitungan terhadap heat gain dinding bangunan terlebih dahulu untuk setiap orientasi dinding. Hasil perhitungan heat gain pada setiap orientasi dinding ditampilkan pada Tabel 4.

Tabel 4. Hasil Perhitungan Heat Gain Fasade Bangunan

\begin{tabular}{lllll}
\hline Lantai & Timur & Selatan & Barat & Utara \\
\hline 1 & $6,990.74$ & $7,768.57$ & $12,988.11$ & $8,245.25$ \\
\hline 2 & $6,750.75$ & $12,460.40$ & $12,988.11$ & $8,245.25$ \\
\hline 3 & $10,370.84$ & $12,460.40$ & $12,988.11$ & $8,245.25$ \\
\hline 4 & $17,241.97$ & $13,002.91$ & $12,988.11$ & $8,245.25$ \\
\hline
\end{tabular}




\begin{tabular}{lllll}
\hline Lantai & Timur & Selatan & Barat & Utara \\
\hline 5 & $17,241.97$ & $13,002.91$ & $12,988.11$ & $8,245.25$ \\
\hline Total & $58,596.27$ & $58,695.19$ & $64,940.56$ & $41,226.27$ \\
\hline
\end{tabular}

Setelah total panas pada tiap-tiap orientasi dinding ditentukan, langkah selanjutnya adalah menentukan batasan nilai watt, untuk mengkategorikasikan nilai panas dinding dimana strategi DSF akan diaplikasikan. Melalui analisa standar deviasi (Widhiarso, n.d.) maka didapatkan batasan minimum kategori tinggi untuk panas dinding pada studi kasus ini. Dinding dengan nilai heat gain di atas 57,035.79 $\mathrm{W}$ akan dikategorikan sebagai dinding dengan nilai heat gain tinggi dan akan diaplikasikan DSF pada dinding tersebut. Sehingga pada skenario kedua ini, dinding timur, selatan dan barat termasuk dinding dengan nilai heat gain yang tinggi dimana akan diaplikasikan strategi DSF.

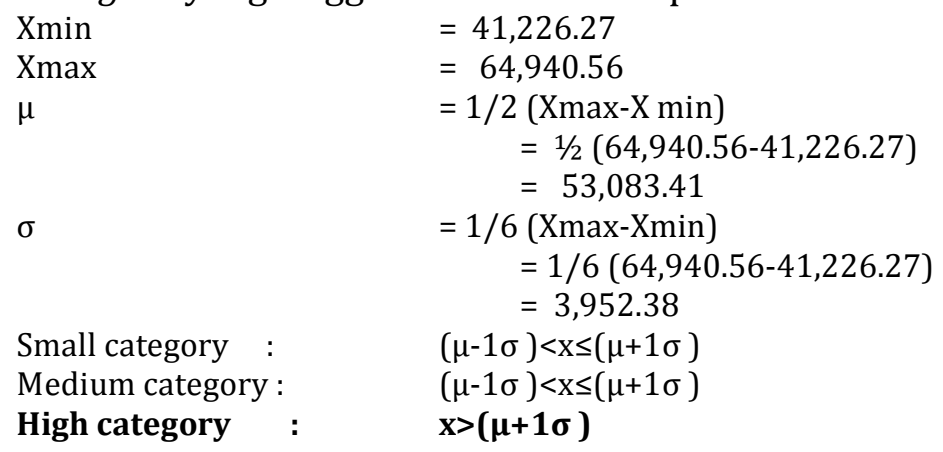

$\mathrm{x}<49,131.03$

$49,131.03<x \leq 57,035.79$

$\mathrm{x}>\mathbf{5 7 , 0 3 5 . 7 9}$

Hasil simulasi untuk scenario pertama dan kedua dirangkum pada Tabel 5.

Tabel 5. Hasil Simulasi Model Dasar dan Model DSF Skenario 1 (S1) dan 2 (S2)

\begin{tabular}{|c|c|c|c|c|c|c|c|c|}
\hline \multicolumn{9}{|c|}{ Cooling energy of the base case model: $250.53(1000 \mathrm{kWh})$} \\
\hline \multicolumn{9}{|c|}{ DSF model simulation results: } \\
\hline \multicolumn{9}{|c|}{ Glazing properties of DSF outer skin } \\
\hline & \multicolumn{2}{|c|}{ Clear glass } & \multicolumn{2}{|c|}{ Reflective glass } & \multicolumn{2}{|c|}{ Laminated glass } & \multicolumn{2}{|c|}{$\begin{array}{l}\text { Double glazed } \\
\text { Low E }\end{array}$} \\
\hline SHGC & \multicolumn{2}{|l|}{0.794} & \multicolumn{2}{|l|}{0.6} & \multicolumn{2}{|l|}{0.495} & \multicolumn{2}{|c|}{0.219} \\
\hline $\begin{array}{l}\text { Direct solar } \\
\text { transmission }\end{array}$ & \multicolumn{2}{|l|}{0.74} & \multicolumn{2}{|l|}{4.97} & \multicolumn{2}{|l|}{0.443} & \multicolumn{2}{|l|}{0.128} \\
\hline $\begin{array}{l}\text { Light } \\
\text { transmission }\end{array}$ & \multicolumn{2}{|l|}{0.86} & \multicolumn{2}{|l|}{0.507} & \multicolumn{2}{|l|}{0.792} & \multicolumn{2}{|l|}{0.229} \\
\hline U-value & \multicolumn{2}{|l|}{5.666} & \multicolumn{2}{|l|}{5.582} & \multicolumn{2}{|l|}{3.161} & \multicolumn{2}{|l|}{1.764} \\
\hline \multicolumn{9}{|c|}{ Cooling energy (1000 kWh) on various air gap width } \\
\hline Air gap & S1 & S2 & S1 & $\mathrm{S} 2$ & S1 & $\mathrm{S} 2$ & S1 & S2 \\
\hline $0.3 \mathrm{~m}$ & 193.11 & 188.81 & 185.26 & 180.7 & 188.42 & 184.62 & 176.25 & 171.08 \\
\hline $0.6 \mathrm{~m}$ & 190.74 & 186.25 & 183.09 & 178.67 & 186.05 & 182.1 & 174.18 & 168.74 \\
\hline $0.9 \mathrm{~m}$ & 184.84 & 184.6 & 179.98 & 176.03 & 181.93 & 180.93 & 173.33 & 165.97 \\
\hline $1.2 \mathrm{~m}$ & 183.34 & 182.77 & 178.74 & 171.86 & 180.26 & 179.27 & 172.16 & 163.62 \\
\hline \multicolumn{9}{|c|}{ Cooling energy reduction (\%) } \\
\hline Air gap & S1 & $\mathrm{S} 2$ & S1 & S2 & S1 & $\mathrm{S} 2$ & S1 & S2 \\
\hline $0.3 \mathrm{~m}$ & 22.92 & 24.64 & 26.05 & 27.87 & 24.79 & 26.31 & 29.65 & 31.71 \\
\hline $0.6 \mathrm{~m}$ & 23.87 & 25.66 & 26.92 & 28.68 & 25.74 & 27.31 & 30.48 & 32.65 \\
\hline $0.9 \mathrm{~m}$ & 26.22 & 27.84 & 28.16 & 30.35 & 27.38 & 29.5 & 30.81 & 33.75 \\
\hline $1.2 \mathrm{~m}$ & 26.82 & 29.09 & 28.66 & 31.4 & 28.05 & 30.64 & 31.28 & 34.69 \\
\hline
\end{tabular}

Penurunan terendah diperoleh pada penggunaan air gap $0.3 \mathrm{~m}$ dan nilai tertinggi diperoleh pada penggunaan air gap $1.2 \mathrm{~m}$. terjadinya penurunan nilai konsumsi energi untuk pendinginan dapat dijelaskan melalui konsep transfer panas. Penambahan layer baru diluar permukaan dinding eksisting dapat memperlambat transfer panas ke dalam 
bangunan. hasil simulasi menunjukkan secara tidak langsung bahwa laju transfer panas berbanding terbalik pertambahan besaran air gap yang pada akhirnya juga ikut mempengaruhi performa thermal bangunan dan konsumsi energi untuk pendinginan bangunan.

Total konsumsi energi bangunan menurun sebanding dengan penurunan nilai SHGC (solar heat gain coefficient) dan U-value material. dalam penelitian ini ditemukan bahwa terdapat faktor lain di luar SHGC dan U-value yang belum ditemukan pada penelitianpenelitian sebelumnya dan dapat mempengaruhi konsumsi energi bangunan yaitu faktor light transmission. Pengaruh light transmission terhadap konsumsi energi bangunan dapat dijelaskan secara singkat melalui proses transfer panas, nilai light transmission yang tinggi mempengaruhi panas dari sinar UV yang masuk ke dalam ruangan sehingga pada akhirnya akan mempengaruhi tingkat konsumsi energi dalam bangunan. Penggunaan kaca double glazed Low E mempunyai pengaruhyang relatif kecil dengan penambahan lebar air gap.

Bentuk bangunan persegi yang cukup kompak dan aplikasi DSF pada skenario pertama pada keempat sisi dan skenario kedua pada ketiga sisi, sehingga perbedaan penurununan energi pendinginan pada skenario pertama dan kedua cukup kecil. Perbedaan tersebut bervariasi antara 6\%.

\section{Kesimpulan}

Dari hasil penelitian ini dapat disimpulkan bahwa strategi DSF ini memungkinkan untuk diaplikasikan pada bangunan di daerah panas lembab seperti Taiwan dengan adanya penurunan energi pada aplikasi di kedua skenario.

Penurunan energi pendinginan bangunan berbanding terbalik dengan ukuran lebar air gap. penambahan lebar air gap memperbesar insulasi thermal pada bangunan sehingga dapat memperlambat laju transfer panas sehingga mampu menurunkan konsumsi energi pendinginan bangunan. ukuran $1.2 \mathrm{~m}$ pada penelitian ini menghasilkan penurunan energi paling besar pada kedua skenario yang diterapkan, penurunan maksimal sebesar $34.69 \%$.

Semakin kecil nilai SHGC dan U-value kaca maka semakin besar penurunan energi yang dapat dicapai. Penggunaan double glazed Low E menghasilkan penurunan energi paling besar diantara material kaca lainnya. Dibandingkan kaca bening biasa, double glazed Low E, rata-rata mampu mengurangi energi pendinginan 19\% lebih besar. Selain itu pada penelitian ini ditemukan bahwa terdapat faktor lain di samping SHGC dan U-value yang dapat mempengaruhi tingkat konsumsi energi bangunan, faktor tersebut adalah light transmission.

\section{Ucapan Terima Kasih}

Program beasiswa Master Double Degree Universitas Brawijaya dan National Central University, Taiwan.

\section{Daftar Pustaka}

Alessi, B. (2008). Double Skin Façade and the its benefits. Copenhagen: Copenhagen Technical Academy.

Azarbayjani, M. (2012). Climatic Based Consideration of Double Skin Façade(Dsf) SystemComparative Analysis of Energy Performance of a Dsf Building in a Mediterranean 
Climate. In Proceedings of the 2012 Symposium on Simulation for Architecture and Urban Design (Vol. 8).

Concina, W., Sadineni, S. B., \& Boehm, R. F. (2011). Development of a Façade Evaluation Facility for Experimental Study of Building Energy. In Proceedings of the ASME 2011 5th International Conference on Energy Sustainability. Presented at the International Conference on Energy Sustainability.

Ho, M.-C. (2011). Green Building Promotion in Taiwan: Current Development and Future Perspectives. Presented at the Architecture and Building Research Institute Ministry of the Interior. Retrieved from http://www.abri.gov.tw

Liu, M. (n.d.). Modelling and Control of Intelligent Glazed Facade. strategic research centre for zero energy buildings. Retrieved from http://www.en.zeb.aau.dk/project_descriptions/phd_projects/modelling_and_contr ol_of_intelligent_glazed_fa\%C3\%A7ade/

Mulyadi, R. (2012). Study on naturally ventilated double-skin facade in hot and humid climate. Nagoya University, Japan.

Tascon, M. H. (2008). Experimental and computational evaluation of thermal performance and overheating in double skin facades (Thesis). University of Nottingham.

Vechaphutti, P.E., T. (n.d.). Simulation of Heat Gain through Building Envelope for Buildings in Hot Humid Climates. ASHRAE. Retrieved from www.ashraethailand.org

Widhiarso. (n.d.). Mengkategorikan Data. Retrieved from widhiarso.staff.ugm.ac.id/files/Mengkategorikan\%20Data.pdf

Wong, P. C. (2008). Natural Ventilation in Double-Skin Façade Design for Office Buildings in Hot and Humid Climate. The University of New South Wales, Australia.

Yagoub, W., Appleton, S., \& Stevens, W. (2010). Case study of double skin façade in hot climates. Presented at the Adapting to Change: New Thinking on Comfort, London.

Yellamraju, V. (2004). Evaluation and Design of Double-Skin Facades for Office Buildings in Hot Climates. Texas A\&M University. 